Japan. J. Med. Sci. Biol., 27, 215-228, 1974

\title{
SUPPLEMENT TO THE PATHOGENICITY AND IMMUNOGENICITY OF AN ATTENUATED VACCINIA VIRUS, STRAIN DIs, IN CYNOMOLGUS MONKEYS
}

\author{
ISAMU TAGAYA, Hiroko AMANO, TOSHIHIKo KOMATSU, \\ NOBUYUKI UCHIDA* AND HIDEO KODAMA* \\ Department of Enteroviruses and *Department of Pathology, National Institute \\ of Health, Nakato, Musashimurayama, Tokyo 190-12, Japan
}

(Received: February 15, 1974)

\begin{abstract}
SUMMARY : The pathogenicity of the DIs virus was compared with those of three other vaccinia virus strains, Lister (Elstree), Ikeda and IHD, by intracerebral inoculation into cynomolgus monkeys. By inoculation of a large amount of the virus into the thalamus and cisterna, the animals receiving the DIs virus remained normal, whereas those receiving the other viruses showed severe clinical symptoms such as anorexia, apathy, coma, and paralysis, and were found moribund or dead within a few days. Histological studies also revealed a big difference in the severity of lesions induced by the DIs virus and those by the other three vaccinia viruses, although the main common finding was leptomeningitis purulenta acuta.

Immunization of cynomolgus monkeys with a single shot of the DIs viurs via the sc, id or im route, followed by a percutaneous challenge with the Ikeda virus, revealed that the skin resistance had not been established (Tagaya et al., 1973). Studies on the dynamics of circulating hemagglutination-inhibiting and neutralizing antibodies, however, indicated that the immunized animals responded more readily and strongly to the challenge with the Ikeda virus than did non-immune animals. This may suggest that the DIs virus induced basic immunity in monkeys, although circulating neutralizing antibody was not detectable and skin reactions by the Ikeda virus were only slightly modified. Thermolabile vaccinia virusneutralizing activity in the serum also appeared or increased by inoculation with the DIs virus as well as with the Ikeda virus. The immunological role of this substance awaits further studies.
\end{abstract}

\section{INTRODUCTION}

Preliminary studies indicated that an attenuated mutant, DIs, of the Dairen-I (DI) strain of vaccinia virus induced mild skin lesions in cynomolgus monkeys by scarification of the skin or intradermal inoculation. Hemagglutination-inhibiting (HI) and neutralizing antibodies were shown in the sera obtained from 1 to 6 weeks postinoculation (p.i.) (Kitamura, Kitamura and Tagaya, 1967). In these studies, however, multi-spot inoculations were given to each monkey, and it was considered necessary to examine in more detail the pathogenicity and immunogenicity of the virus in mon-

Partly aided by a special grant from the Science and Technology Agency and the Ministry of Health and Welfare.

多ヶ谷勇・天野浩子・小松俊彦（国立予防衛生研究所 腸内ウイルス部）

内田信之・児玉栄夫（国立予防衛生研究所 病理部） 
keys before a possible applicability of the mutant to human vaccination is considered. Further studies were carried out to examine the pathogenicity of the DIs virus in monkeys, inoculating a large amount of the virus intracerebrally, intravenously or percutaneously. It was revealed that the virus was also highly attenuated to cynomolgus monkeys. Immunization of monkeys with a single shot of the DIs virus by various routes, followed by percutaneous challenge with the ordinary calf lymph smallpox vaccine, was then carried out. It was indicated that the DIs virus could not immunize monkeys strong enough to resist percutaneous challenge with the ordinary vaccinia virus, although circulating antibody response suggested the induction of basic immunity by the DIs virus. A summary of the studies was reported at the International Symposium on Smallpox Vaccine, Bilthoven 1972 (Tagaya et al., 1973). The present report deals with supplementary data on the pathogenicity of the DIs virus in comparison with the other three strains of vaccinia virus as well as complete data on the dynamics of circulating antibodies in monkeys by immunization with the DIs virus and challenge with the Ikeda virus, which were not available at the time of the symposium.

\section{MATERIALS AND METHODS}

Viruses: The DI and DIs viruses at the 24 to 26 th passage through the chorioallantonic membrane (CAM) of conventional fertile hen's eggs were used. The Ikeda, Lister (Elstree) and IHD (hemagglutinin positive) strains of vaccinia virus were used as the homogenate of infected CAM's of the 2nd, 3rd and first passage, respectively, performed in our laboratory from the following original seeds. The original Lister virus was the lyophilized International Reference virus; the original Ikeda virus a lot of lyophilized calf lymph vaccine prepared by the Kitasato Institute. The IHD virus kept in our laboratory was with the passage history M25E3 (25 passages through the mouse and 3 passages through CAM). A commercial lot of liquid calf lymph vaccine prepared with the Ikeda virus was also used for challenging DIs-immunized monkeys.

Titration of infectivity: The plaque titration of the virus in CE cell monolayers was described elsewhere (Ueda et al., 1972; Tagaya et al., 1974). For the recovery and quantification of virus from inoculated monkeys the serum or a $10 \%$ homogenate of each organ was diluted decimally and $0.2 \mathrm{ml}$ each was inoculated onto 3 to 4 CAM's of 12-day egg per dilution. Phosphate-buffered saline (PBS), $\mathrm{pH} 7.4$, containing gelatin at $0.2 \%$ was used as the diluent for virus materials.

Titration of circulating neutralizing antibody: This was described earlier (Ueda et al., 1972).

Titration of HI antibody: The micro-method in the disposable tray was used with PBS as diluent. For hemagglutinin (HA) titration, duplicate serial twofold dilutions of the antigen (homogenate of DI-infected CAM's) were made in $0.025 \mathrm{ml}$ with a standardized Takátsy loop, starting from a 1:10 dilution. To one series, $0.025 \mathrm{ml}$ each of 1:30 diluted normal rabbit serum and to the other $0.025 \mathrm{ml}$ each of $1: 30$ diluted antivaccinia rabbit serum was added. The sera were inactivated at $56 \mathrm{C} 30$ min before use. To each well $0.025 \mathrm{ml}$ of a $0.2 \%$ erythrocyte suspension from vaccinia HA-sensitive fowls was then added and the plate was shaken on a vibrator for 5 sec. After 60-min incubation at $37 \mathrm{C}$ the results were read and the highest dilution of the antigen showing complete hemagglutination pattern in the normal rabbit 
serum was taken as the endpoint. The specificity of this hemagglutination was checked by its inhibition in the immune rabbit serum line. For HI test serial twofold dilutions of a serum was set up in duplicate. To one series $0.025 \mathrm{ml}$ of 4 units of HA was added and to the other an equal amount of normal rabbit serum diluted 1:30 was added, which served as test serum control to examine the presence of non-specific hemagglutination. The plate, after being shaken, was incubated at $36 \mathrm{C}$ for $30 \mathrm{~min}$ and then $0.025 \mathrm{ml}$ of a $0.2 \%$ fowl erythrocyte suspension was added to each well. The plate was shaken and incubated at $36 \mathrm{C}$ for $60 \mathrm{~min}$ and $\mathrm{HI}$ titer was expressed as the highest dilution of a serum showing complete inhibition of hemagglutination. When serum control showed non-specific hemagglutination, $0.5 \mathrm{ml}$ of the original serum was absorbed with $0.025 \mathrm{ml}$ of packed fowl erythrocytes at $37 \mathrm{C}$ for $30 \mathrm{~min}$. The red blood cells were removed by centrifugation at $2,500 \mathrm{rpm}$ for $7 \mathrm{~min}$ and the supernatant served as absorbed serum. Parallel titration of HA used for the test was always set up.

Inoculation of monkeys: Cynomolgus monkeys of both sexes with body weights of about 2 to $3 \mathrm{~kg}$ were used. Intracerebral inoculation was carried out by injecting $0.25 \mathrm{ml}$ of a test material into the cisterna and $0.5 \mathrm{ml}$ into one side of the thalamus. Monkeys were sacrificed at moribund or 10 days p.i. Bleeding was made before inoculation and at autopsy. Histological examinations were made by the ordinary technique with the organs obtained at autopsy.

Fluorocarbon treatment of vaccinia-infected CAM homogenate: Daiflon S3 (trifluorotrichloro-ethane, Daikin Kogyo Co. Ltd.), cooled in a deep freezer at $-20 \mathrm{C}$ was added to homogenate of infected CAM's at a final concentration of $50 \%$ and mixed in a blender under cooling with ice. The water phase was separated by light centrifugation. Pre-cooling of Daiflon S3 was necessary to minimize the loss of the infectivity of the homogenate of DIs-infected CAM's.

\section{RESUlts}

\section{Intracerebral Inoculation of Cynomolgus Monkeys with the DIs Virus or Three Other Strains of Vaccinia Virus}

As reported in a previous publication (Tagaya et al., 1973), cynomolgus monkeys inoculated with the DIs virus $\left(10^{8 \cdot 0} \mathrm{TCID}_{50} / \mathrm{ml}\right)$ intravenously or percutaneously remained normal except for local reddening 6 to 8 days p.i. in those inoculated by multiple pressures; but those inoculated intracerebrally (intrathalamic $0.4 \mathrm{ml}$ and intracisterna $0.25 \mathrm{ml}$ ) showed fever 3 to 6 days p.i. with lassitude and anorexia, from which they appeared to recover later. An experiment was designed then to compare the pathogenicity of the DIs virus with those of the other three vaccinia viruses by intracerebral inoculation into cynomolgus monkeys. Homogenate of infected CAM's was treated two or three times with fluorocarbon before use. The results are shown in Table I, which includes those on the DIs virus reported in a previous publication (Tagaya et al., 1973). The animals inoculated with the Ikeda, Lister or IHD viruses showed severe clinical symptoms from 1 to 2 days p.i. Out of three monkeys inoculated with the IHD virus, one was found dead the day following inoculation and excluded from evaluation, because the death was considered to have been due to inoculation trauma. The other two monkeys, however, were seriously ill; one of them was found dead and the other was moribund 2 days p.i. Those inoculated with the 


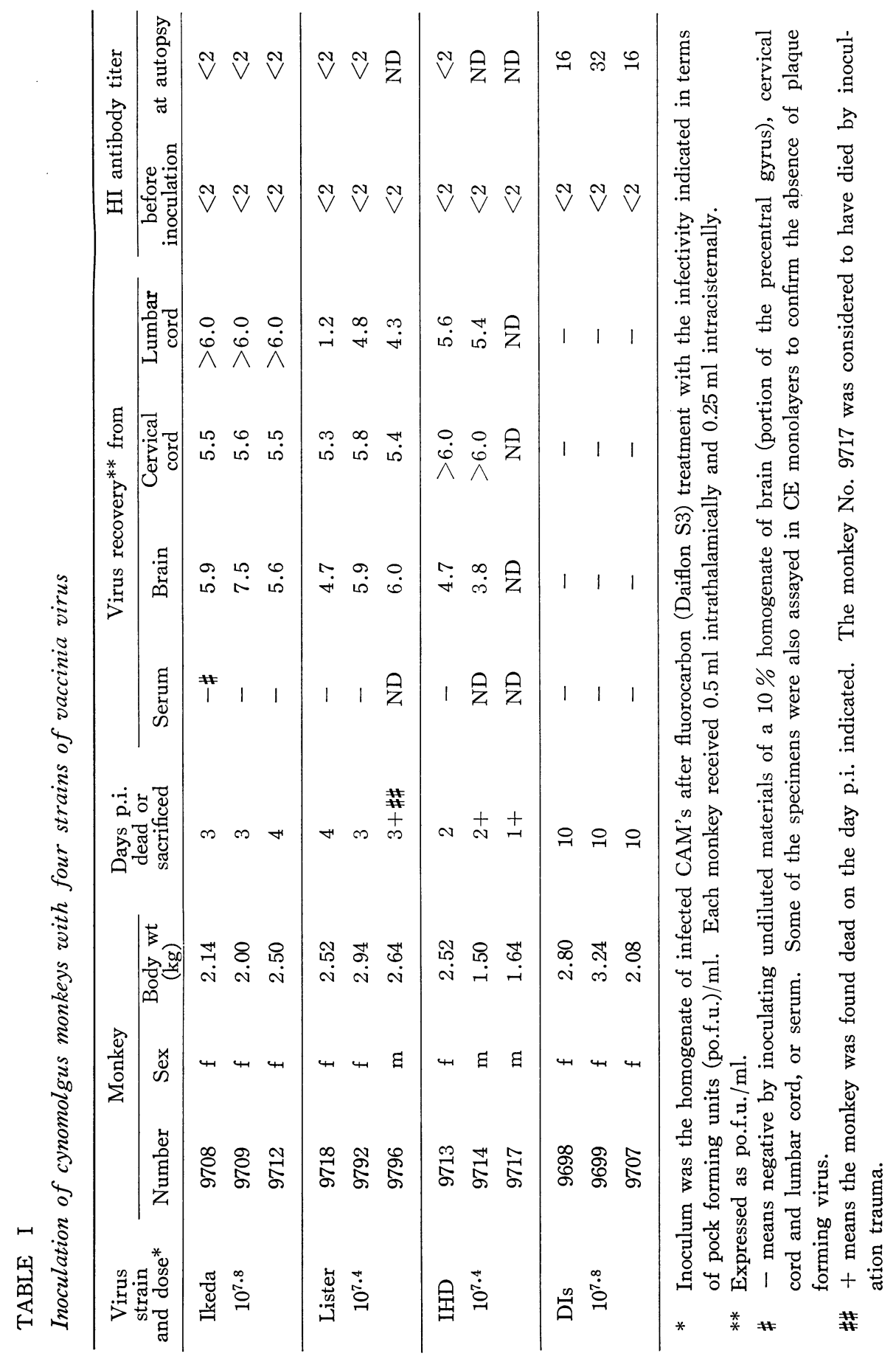


Ikeda or Lister viruses were also moribund or deceased 3 to 4 days p.i., whereas those inoculated with the DIs virus remained apparently normal without rise of body temperature during the observation period of 10 days. Vaccinia virus was isolated from all specimens of the brain and spinal cord of the animals inoculated with the Ikeda, Lister or IHD viruses; the virus contents of these organs were high except the lumbar cord of one monkey inoculated with the Lister virus. Vaccinia virus was not detectable in the serum of these animals. Attempts at virus isolation with the specimens collected from those inoculated with the DIs virus 10 days p.i. were unsuccessful. HI antibody was not detectable in the serum of those inoculated with the Ikeda, Lister or IHD viruses due to the early death or sacrifice of the animals. Rise in circulating HI antibody was confirmed in the serum of those inoculated with the DIs virus, indicating multiplication of the virus in the animals in spite of no development of clinieal symptoms.

The results indicate that the DIs virus is far less pathogenic to cynomolgus monkeys by intracerebral inoculation than the other three vaccinia strains, two of which have been extensively used for human vaccination in this country or in many other countries in the world.

\section{Histological Examination of Organs of Monkeys Inoculated with the DIs or Other Vaccinia Virus Strains}

There was no other particular gross findings than turbidity of the leptomeninges and dilatation of the meningeal vessels in the central nervous system. Major parts examined microscopically were parietal lobe including sulcus centralis, basal ganglia, midbrain, cerebellum with pons, medulla, cervical and lumbar enlargements of the spinal cord in the central nervous system, and a few visceral organs such as liver, spleen, lung, lymph nodes, etc. The main pathological change was leptomeningitis in all the monkeys examined. The animals inoculated with the Ikeda, Lister or IHD viruses, however, had marked leptomeningitis of similar severities. These changes were far severer than those in the animals inoculated with the DIs virus. Microscopic changes in the leptomeninges of the animals inoculated with the virulent viruses were typical fibrino-purulent leptomeningitis with marked congestion in the vessels of the subarachnoid spaces and with fibrino-purulent exudate containing numerous polymorphonuclear leukocytes, moderate lymphocytes and mononuclear cells. The exudate was abundant in the sulci of the severe cases such as Nos. 9712, 9714, and 9796 (Fig. 1). Purulent inflammation extended to the choroidal plexus (Nos. 9712, 9713, and 9796) (Fig. 2) and also continued slightly under the subependymal space (No. 9712).

As anticipated from the clinical observations, the monkeys inoculated with the DIs virus revealed only slight leptomeningitis with infiltration with predominant round cells around the vessels in the pia-arachnoid spaces (Fig. 3). There were no or a few polymorphonuclear leukocytes in such infiltration. The difference in the type of the infiltrating cells in the leptomeninges between the DIs virus group and three other virus groups of animals may have been due to the different pathogenicities of the viruses and in part to the time of autopsy after inoculation. There were hemorrhage and acute purulent inflammation in the direct vicinity of the inoculation site in the IHD, Lister and Ikeda virus groups of animals and slight ones in the DIs virus group. Besides these findings there observed in all the monkeys extremely slight edema around the small vessels, but neither changes in the neurons nor demyelination in the paren- 


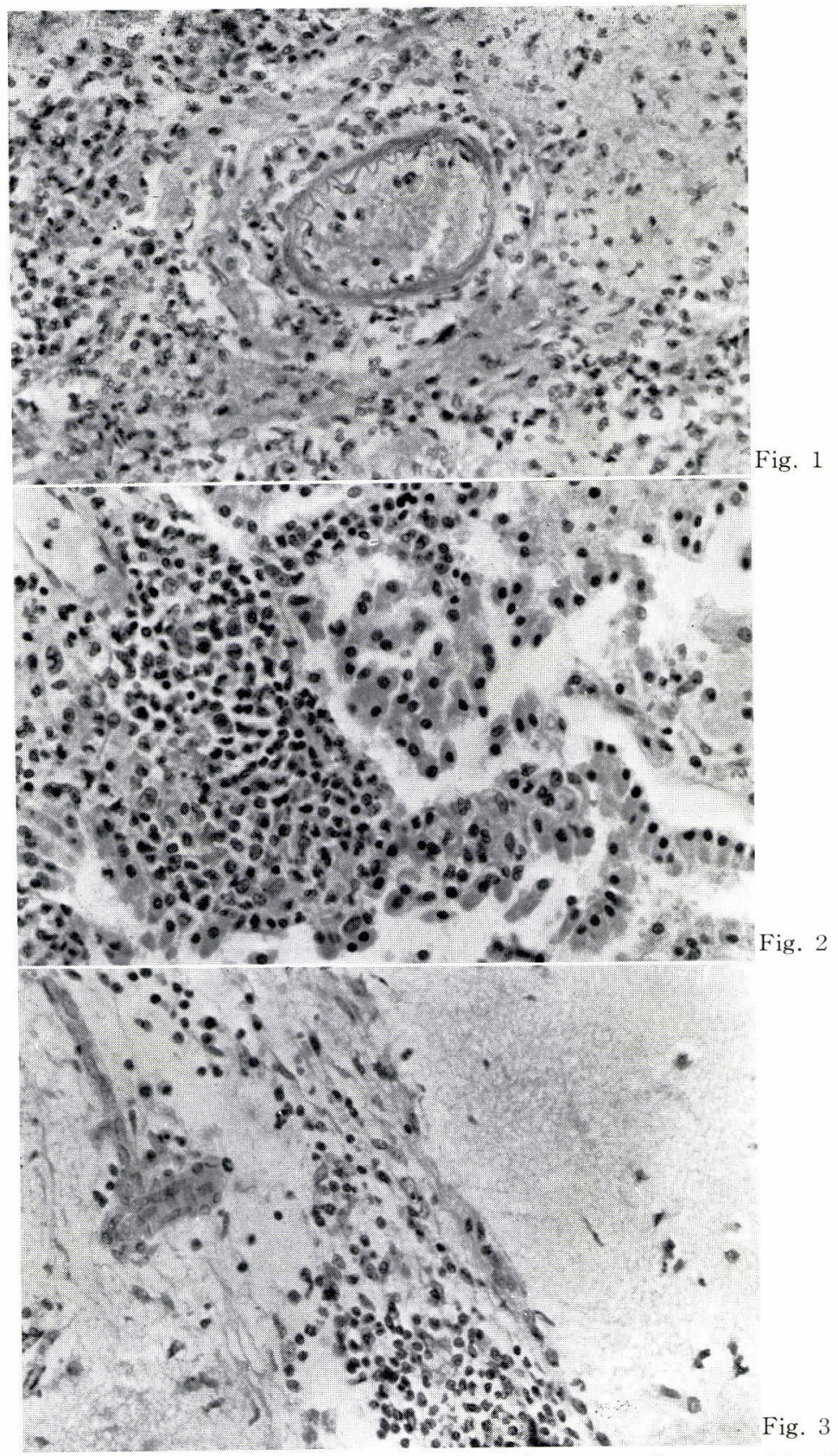

Fig. 1. Acute purulent leptomeningitis with non-specific panangitis of small artery in the brain of a cynomolgus monkey (No. 9796) incculated with the Lister virus.

Fig. 2. Acute purulent leptomeningitis extending to choroid plexus in the same monkey shown in Fig. 1.

Fig. 3. Slight subacute leptomeningitis in the brain of a cynomolgus monkeys (No. 9698) inoculated with the DIs virus. 


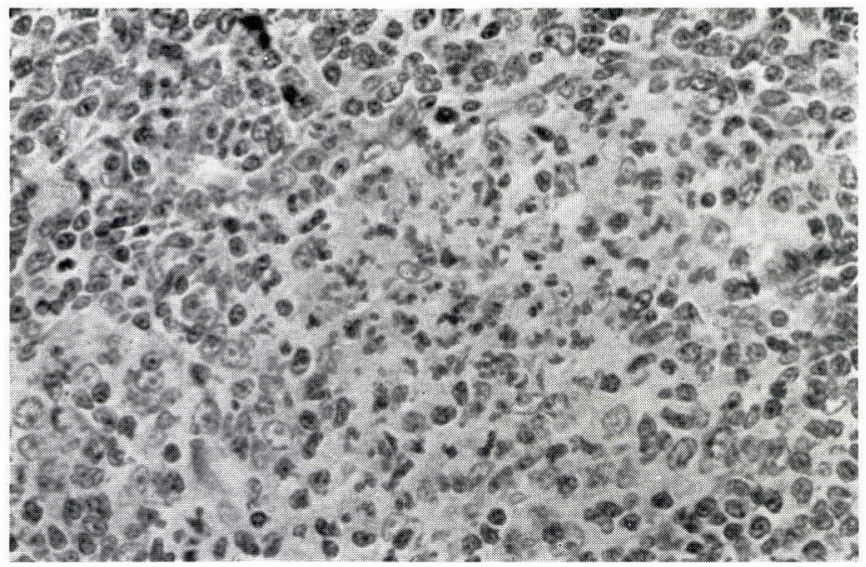

Fig. 4. Small accumulation of polymorphonuclears like abscess in the lymph follicle of the spleen of a cynomolgus monkey (No. 9713) inoculated with the IHD virus.

chyma of the brain except the inoculation site.

The spleen of the animals inoculated with any of the three viruses other than the DIs virus revealed histologically acute splenitis. Although there was a little difference in the severity of the changes among monkeys, they showed moderate congestion, accumulation of remarkably a large number of polymorphonuclear leukocytes in the cellular red pulp and slight atrophy of lymphoid tissues with decreased number of the reaction centers. Interesting findings were that the reaction centers were sometimes necrotic with a small accumulation of polymorphonuclear leukocytes showing an appearance of small abcess (Fig. 4). On the contrary the spleens of the animals inoculated with the DIs virus did not show any changes such as acute infectious splenitis.

The lungs of the two monkeys each inoculated with the IHD or Lister viruses respectively showed slight inflammatory changes in the alveolar septa.

\section{Antibody Response of Cynomolgus Monkeys after Immunization with the DIs Virus and Challenge with the Ikeda Virus}

Twelve monkeys were divided into four groups of three monkeys; nine of them were inoculated with homogenate of DIs-infected CAM's treated twice with fluorocarbon before use. The infectivity of the virus preparation was $10^{7 \cdot 7} \mathrm{PFU} / \mathrm{ml}$. The first group received $1.0 \mathrm{ml}$ subcutaneously into the right upper arm, the second group $0.2 \mathrm{ml}$ intradermally into the right upper arm and the third group $1.0 \mathrm{ml}$ intramuscularly into the right shoulder. The 4 th group were left uninoculated and kept in the same room as room mates. Each monkey was kept in a separate cage. Those inoculated subcutaneously or intramuscularly showed no recognizable local reaction, while each of those inoculated intradermally showed a pinpoint induration of about $2 \mathrm{~mm}$ diameter, followed by scab formation. All the monkeys except one remained in good conditions until the challenge with the Ikeda virus 13 weeks later. One animal in the first group died 7 weeks p.i. due to an unspecified cause. After 13 weeks these monkeys were inoculated with a commercial lot of liquid calf lymph vaccine prepared with the Ikeda virus by multiple pressure on the left upper arm. Two 
TABLE II

Local reaction of the monkeys after cutaneous inoculation with smallpox vaccine

\begin{tabular}{|c|c|c|c|c|c|}
\hline \multirow[t]{2}{*}{ Group } & \multirow{2}{*}{$\begin{array}{l}\text { Pretreatment } \\
\text { with } \\
\text { DIs virus }\end{array}$} & \multirow{2}{*}{$\begin{array}{l}\text { Identity } \\
\text { of } \\
\text { monkey }\end{array}$} & \multicolumn{3}{|c|}{$\begin{array}{l}\text { Diameters of induration or } \\
\text { swelling (mm) at days } \\
\text { after smallpox vaccine }\end{array}$} \\
\hline & & & 4 & 7 & 9 \\
\hline \multirow{2}{*}{ I } & \multirow{2}{*}{$\begin{array}{l}\text { Subcutaneous } \\
1.0 \mathrm{ml} \\
\left(10^{7.7} \mathrm{PFU}\right) \\
\end{array}$} & 9423 & 7.5 & $13.0(\mathrm{~A})$ & $9.0 \quad(\mathrm{~A})$ \\
\hline & & 9438 & 3.0 & $3.5(-)$ & $2.0^{*}(-)$ \\
\hline \multirow{3}{*}{ II } & \multirow{3}{*}{$\begin{array}{l}\text { Intradermal } \\
0.2 \mathrm{ml} \\
\left(10^{7.0} \mathrm{PFU}\right)\end{array}$} & 9429 & 6.0 & $12.0(-)$ & $10.5^{* *}(-)$ \\
\hline & & 9430 & 4.0 & 11.0 (B) & $7.0^{* *}(\mathrm{~B})$ \\
\hline & & 9431 & 6.0 & $16.5(-)$ & $11.0^{* *}(-)$ \\
\hline \multirow{3}{*}{ III } & \multirow{3}{*}{$\begin{array}{l}\text { Intramuscular } \\
1.0 \mathrm{ml} \\
\left(10^{7.7} \mathrm{PFU}\right)\end{array}$} & 9425 & 6.5 & $12.0(\mathrm{~A})$ & $8.0^{* *}(\mathrm{~B})$ \\
\hline & & 9427 & 6.0 & $10.0(-)$ & $7.0^{* *}(-)$ \\
\hline & & 9428 & 6.0 & 10.5 (B) & $7.5^{* *}(-)$ \\
\hline \multirow{3}{*}{ IV } & \multirow{3}{*}{$\begin{array}{l}\text { None } \\
\text { (room mate) }\end{array}$} & 9433 & 5.0 & $8.5(\mathrm{~A})$ & $11.0 \quad(\mathrm{~A})$ \\
\hline & & 9435 & 5.0 & $12.5(-)$ & $19.0 \quad(-)$ \\
\hline & & 9436 & 6.0 & 13.5 (B) & $11.0 \quad(\mathrm{~B})$ \\
\hline \multirow{2}{*}{ V } & \multirow{2}{*}{$\begin{array}{l}\text { None } \\
\text { (fresh) }\end{array}$} & 8887 & 5.5 & $12.0(\mathrm{~A})$ & $11.0 \quad(\mathrm{~A})$ \\
\hline & & 8988 & 7.0 & 15.0 (B) & $10.5 \quad(\mathrm{~A})$ \\
\hline
\end{tabular}

(A): Swelling of an axillary lymph node of a sparrow- to quail-egg size.

(B): Swelling of an axillary lymph node of a bean to soybean size.

$(-)$ : No swelling of axillary lymph node.

* : Skin lesion almost completely cured.

** : Slight flat swelling without induration.

[Cited from the previous publication (Tagaya et al., 1973) by the permission of the publisher.]

fresh monkeys were also inoculated as additional controls. The summary of the local reactions of each monkey having appeared in a previous report (Tagaya et al., 1973) is cited here with the permission of the publisher (Table II). All the animals showed erythema and induration quite similar to those observed after the human primary vaccination. However, some of the animals immunized with the DIs virus appeared to show the accelerated wane of local reactions with an earlier scab formation 9 days p.i. compared with the control room mates or fresh animals. Some of the monkeys showed swelling of the axillary lymph node. The results indicated that the immunization of monkeys with the DIs virus did not induce skin resistance strong enough to modify the local reactions to percutaneous inoculation with the ordinary smallpox vaccine 13 weeks later.

The HI antibody response of the monkeys is shown in Fis. 5. By immunization with the DIs virus all the animals responded with a rise in circulating HI antibody, attaining the highest titer 2 to 3 weeks p.i. By percutaneous inoculation with the calf lymph vaccine the antibody rose again, reaching a peak 2 weeks p.i. The time course of the HI antibody response after the challenge with the Ikeda virus was accelerated in animals immunized with the DIs virus compared with the control animals, 

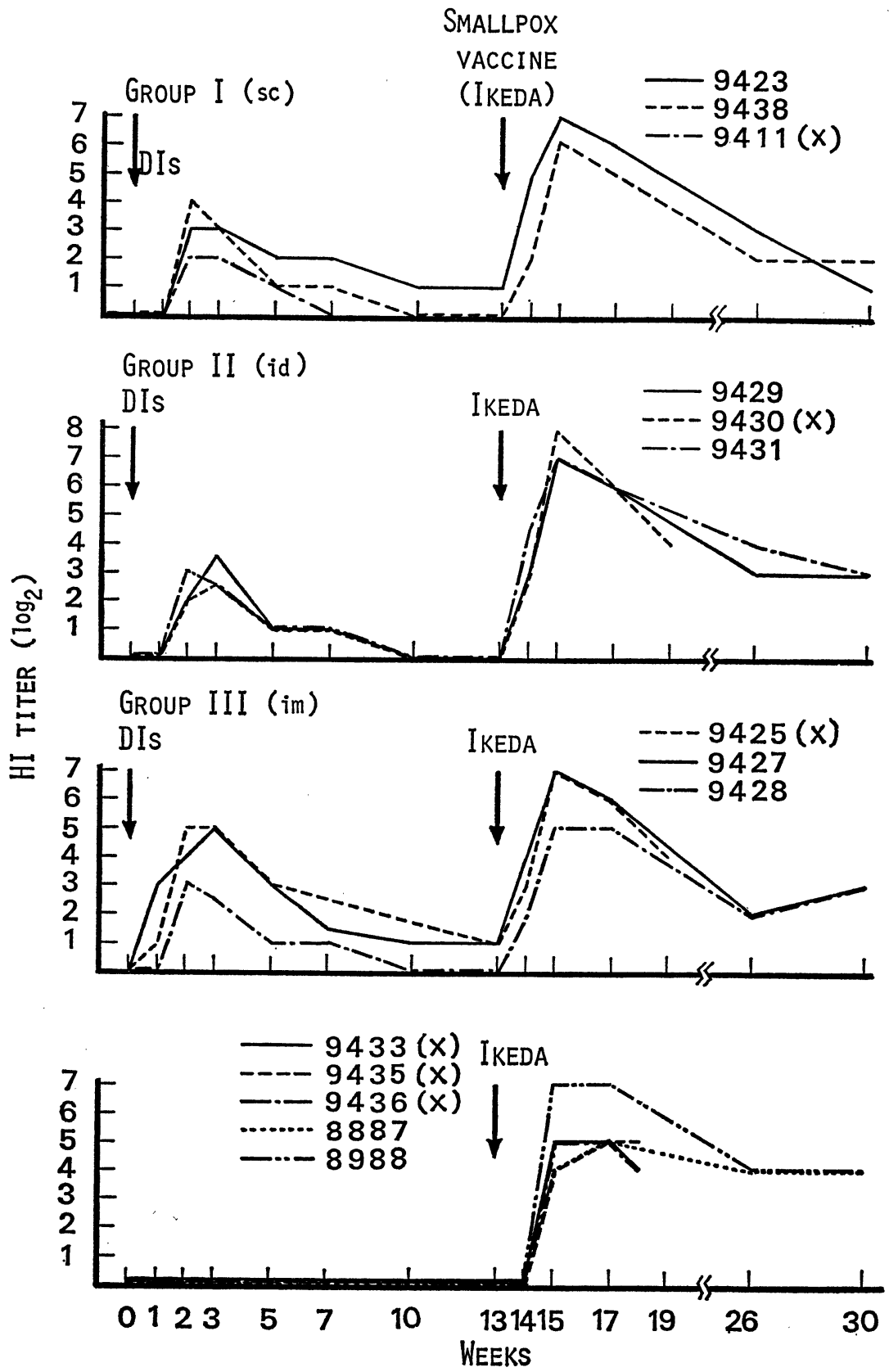

X: SACRIFICED

Fig. 5. HI antibody response of cynomolgus monkeys after inoculation of the DIs and Ikeda viruses. 


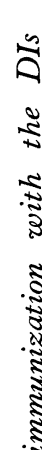

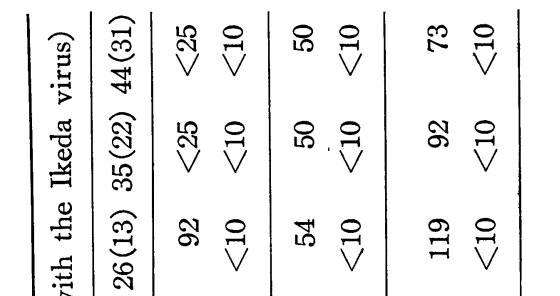

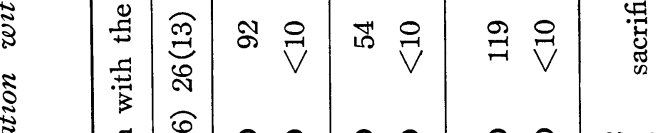

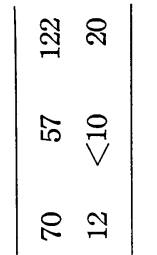

|

荧

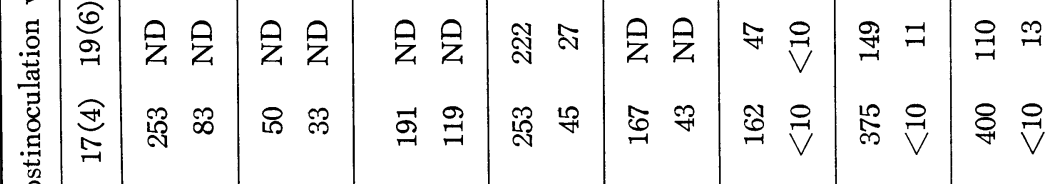

离

品

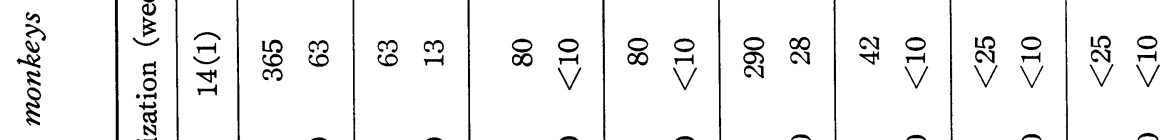

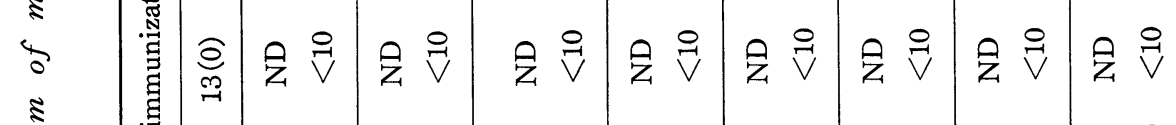

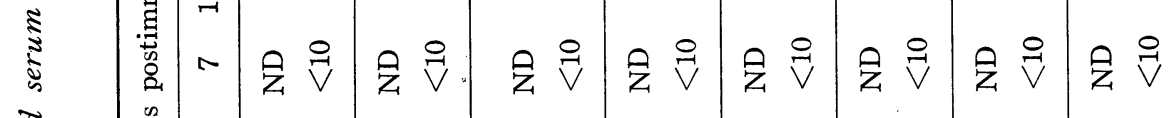

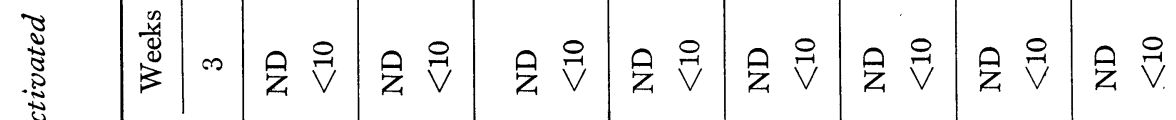

ปัป

竞:总

ฐ

告

₹

จุ

先 $\frac{2}{\sqrt{2}}$

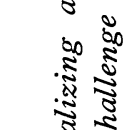

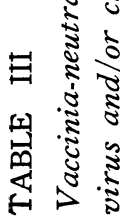

保

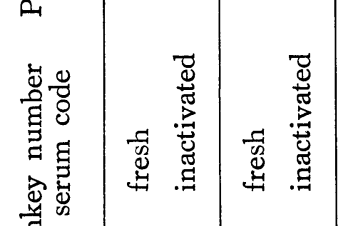

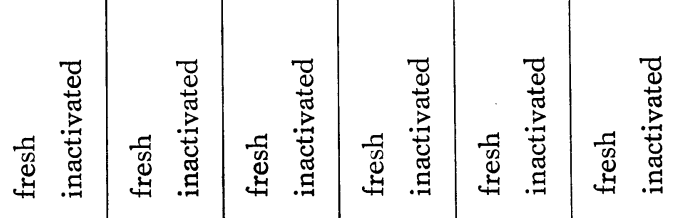

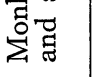

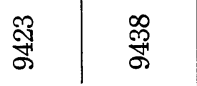

急

$\overrightarrow{\text { ș }}$

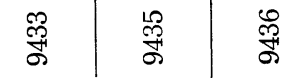

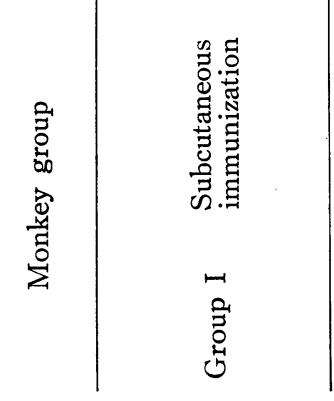

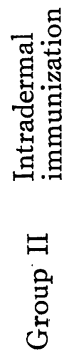

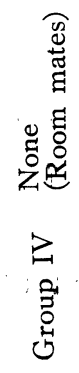


as shown by the significant rise in the antibody one week p.i., when no antibody was detectable in the control animals.

Neutralinzing antibody was determined with portions of the monkey sera and the titers were included in a previous report (Tagaya et al., 1973). The test was completed later with all the specimens and some corrections were also made by replicate tests. Circulating neutralizing antibody was not detectable in the monkeys given only one shot of the DIs virus, but after challenge with the Ikeda virus a rapid rise was observed, reaching the peak 2 weeks later with a rather rapid decline thereafter. One week after the challenge, five of the eight immunized monkeys showed signifi-
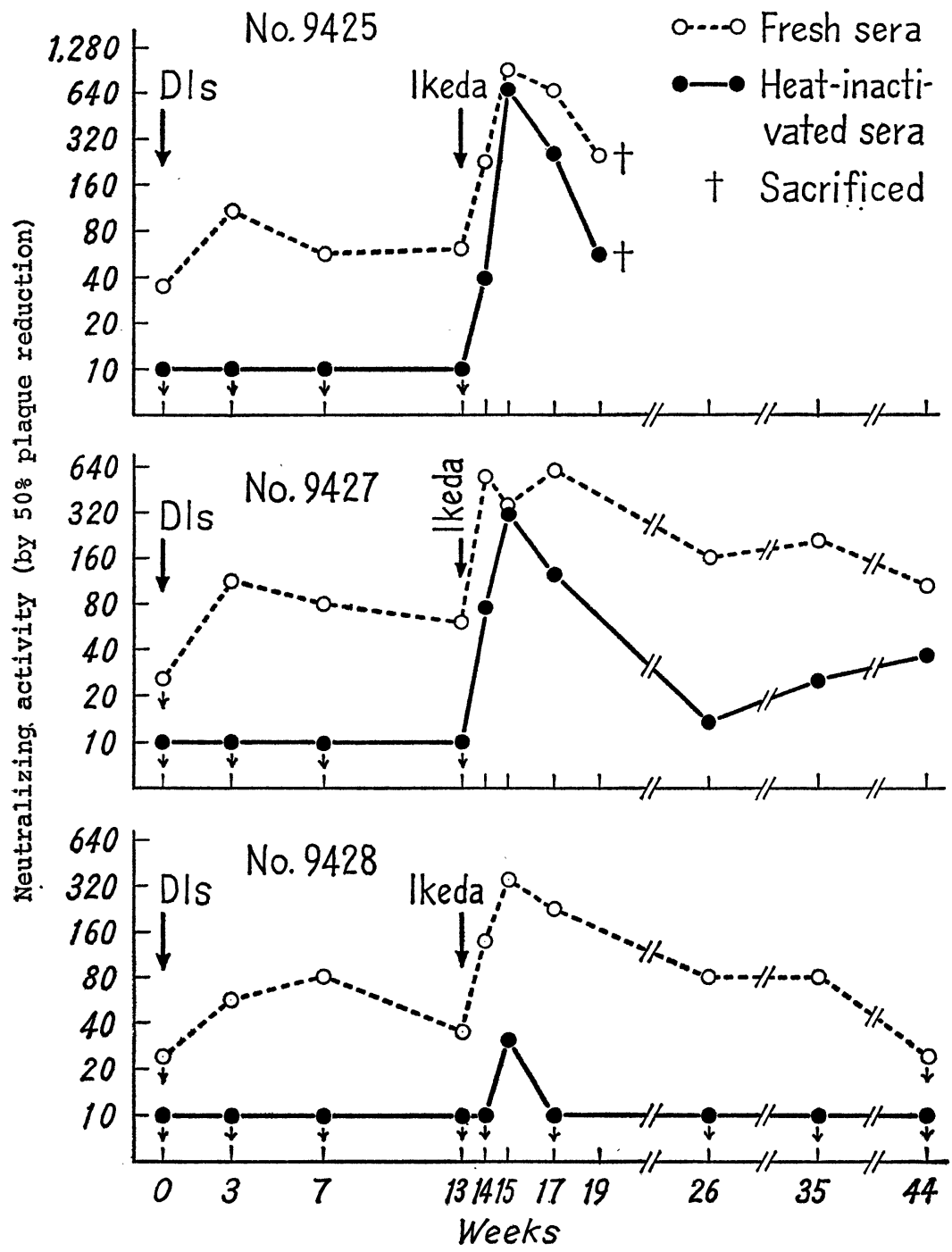

Fig. 6. Vaccinia virus neutralizing activity of the fresh and heat-inactivated sera of monkeys after intramuscular inoculation of the DIs virus and percutaneous challenge with the Ikeda virus. 


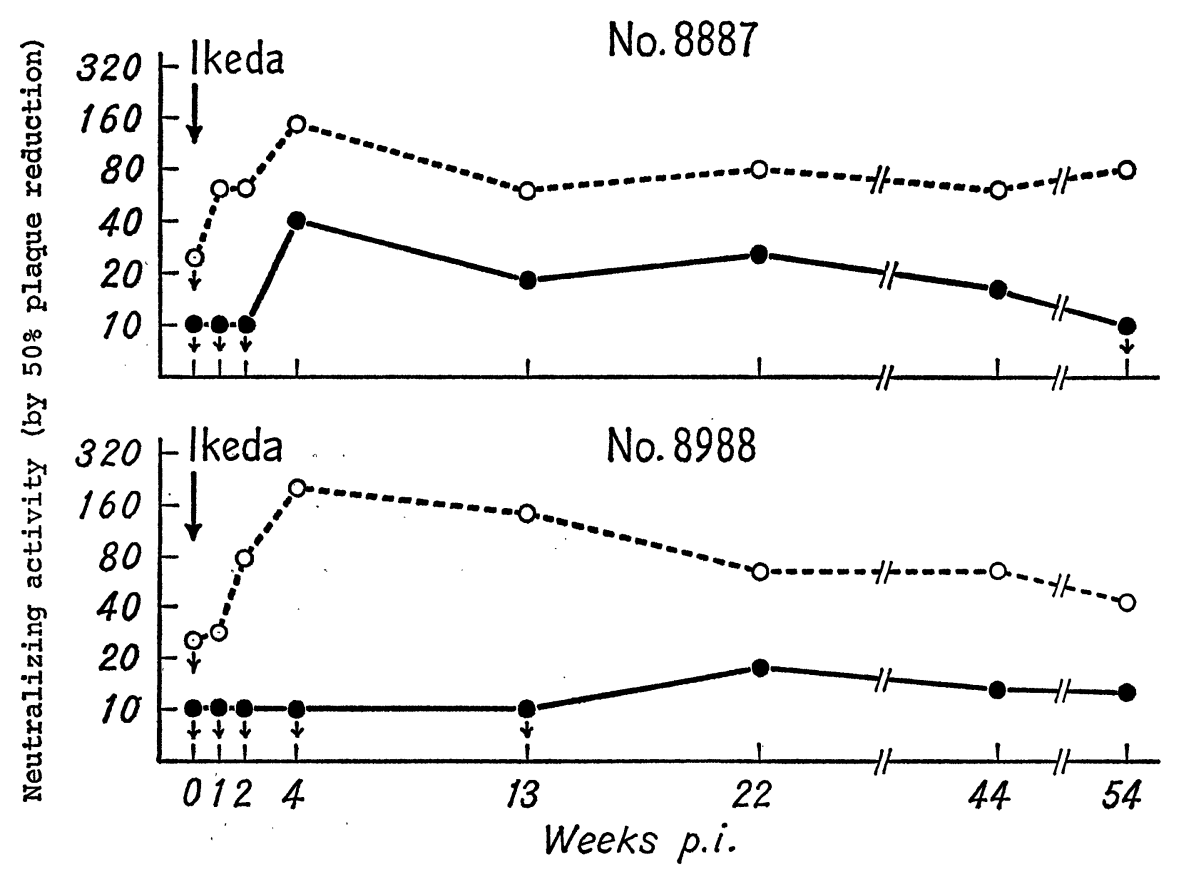

Fig. 7. Vaccinia virus-neutralizing activity of the fresh and heat-inactivated sera of monkeys after percutaneous inoculation of the Ikeda virus.

cantly increased antibody, while none of the control animals did (Table III, Figs. 6 and 7). The high titers of neutralizing antibody induced in the immunized animals by the challenge with the calf lymph vaccine, however, did not last long but declined rather rapidly. One monkey of the intramuscular immunization group responded poorly with a low titer of the antibody only in the serum collected 2 weeks after the challenge (Fig. 6). The neutralizing antibody response of the control animals was generally low (Table III, Fig. 7).

Another intersting finding was obtained with regard to the dynamics of thermolabile inhibitor of vaccinia virus in the serum of monkeys by inoculation with the DIs virus and challenge with the Ikeda virus. It has been found in our laboratory that some of fresh sera of cynomolgus monkeys reduced the plaque number by vaccinia virus in CE cultures, when mixed with virus and incubated before inoculation as in the neutralization test. In the present experiment neutralizing activities of both fresh and heat-inactivated sera were titrated in parallel. The dynamics of thermolabile and thermostable neutralizing activities in the serum of the monkeys of Group III (im immunization) and Group V (non-immune) are shown in Figs. 6 and 7, as these animals were followed for longer periods. The data on the sera of the animals of the other groups are summarized in Table III. By im inoculation of the DIs virus, circulating thermolabile neutralizing activity increased in all three monkeys, although one of them had the same activity of lower titer in the preimmunization serum. However, thermostable neutralizing antibody was not detectable in these sera before challenge with the Ikeda virus. By percutaneous inoculation with the Ikeda virus 
both activities increased rapidly as shown in Fig. 6. The rise in thermolabile as well as thermostable neutralizing activities was also observed in the serum of control nonimmune monkeys after inoculation with the Ikeda virus, and thermolabile neutralizing activity roughly paralleled thermostable neutralizing antibody, but the former appeared earlier and seemed to last longer than the latter. Appearance of neutralizing antibody in this group of monkeys was irregular and the titer generally low (Table III, Fig. 7). The specificity and immunological role of this thermolabile vaccinia virus-neutralizing factor in the serum must await further study. The present observation appears to suggest that some sort of immune status, as shown by the antibody response to the challenge with the Ikeda virus, was induced by one shot of the DIs virus, although circulating neutralizing antibody did not reach a detectable level.

\section{Discussion}

Extremely low pathogenicity of the DIs virus in rabbits, mice, guinea pigs and chicks or chickens was established as reported in a previous publication (Tagaya, Kitamura and Sano, 1961). The low virulence of the virus was confirmed also in cynomolgus monkeys by iv, im, sc and id inoculations (Tagaya et al., 1973). Intracerebral inoculation, however, induced in some monkeys mild clinical symptoms as reported previously (Tagaya et al., 1973), although far milder than those induced by other strains of vaccinia virus. When monkeys were sacrificed 10 days p.i., recovery of virus from the brain and spinal cord was not successful. Histologically, however, leptomeningitis purulenta acuta was observed, which may have accounted for manifestation of the clinical symptoms. This may indicate that the DIs virus multiplied to some extent in the leptomeninges near the inoculation site, but some defence mechanism including immune response and interferon production as well as low replicability of the virus in primate cells as suggested by in vitro studies (Tagaya et al., 1973) interrupted the multiplication of the virus. On the contrary, the other strains of vaccinia virus examined, including those available for human vaccination, killed the animals within a few days p.i., as reported in previous publications (Aldershoff, Pondman and Pot, 1929; Hurst and Fairbrother, 1930; McIntosh and Scarff, 1930; Eckstein, 1931). This was confirmed by extensive studies, of which a preliminary report appeared elsewhere (Hashizume et al., 1973).

Immunization of monkeys with a single injection of the DIs virus by the sc, id or im route did not induce skin resistance to challenge by the calf lymph smallpox vaccine of the Ikeda strain, although local reactions appearred to be accelerated to some extent compared with those in non-immune animals (Tagaya et al., 1973). HI antibody response was observed, but circulating neutralizing antibody was not detectable by DIs immunization. By challenge with the Ikeda virus, however, immunized animals responded with a rapid rise in both $\mathrm{HI}$ and neutralizing antibodies, which reached the peak 2 weeks after challenge. This may suggest that the DIs virus induced a certain degree of basic immunity to poxvirus infection, though not strong enough to prevent or modify skin reaction by the Ikeda virus. Before the applicability of the DIs virus to human vaccination is assessed, more studies are necessary to improve its immunity-inducing capacity in primates, although it is considered as one of the safest vaccinia virus to man from the results of intracerebral inoculation 
into monkeys.

The presence of a thermolabile vaccinia virus-neutralizing factor in the serum of some monkeys and the appearance or increase of this activity by the inoculation of the DIs virus or Ikeda virus appear to provide a new field of study. The nature of the thermolabile inhibitor of variola virus in normal guinea pig or rabbit sera has recently been studied by Kitamura and his associates (Kitamura, Miyagawa and Tanaka, 1973; Kitamura, Tanaka and Sugane, 1973), and they also have confirmed that this inhibitor increased after infection with vaccinia virus (personal communication).

\section{REFERENCES}

Aldershoff, H., Pondman, A. B. F. A. ANd Pot, A. W. (1929): Injection intracérébrale du virus vaccinal chez le singe. Propriétés de la neurolapine. Ann. Inst. Pasteur, 43, 1268-1277.

ECKSTEIN, A. (1931): Klinisch-experimentalle Untersuchungen über die Vaccinations-encephalitis. VI. Experimentall erzeugte Vaccineencephalitis beim Affen. Z. Hyg. Infekt., 112, 151-177.

Hashizume, S., Morita, T., Yoshizawa, H., Suzuki, K., Arita, M., Komatsu, T., AMANO, H, AND TAGAYA, I. (1973): Intracerebral inoculation of monkeys with several vaccinia strains: An approach to the comparison of different strains. Symp. Series. immunobiol. Standard., 19, 325-331.

HURST, E. W. AND FAIRBRotheR, R. W. (1930): Experimental vaccinial encephalitis in the monkey and the rabbit, with special reference to the problem of encephalitis following vaccination in man. J. Pathol. Bacteriol., 33, 463-481.

KitAmURA, T., KitAmuRA, Y. AND TAGAYA, I. (1967): Immunogenicity of an attenuated strain of vaccinia virus on rabbits and monkeys. Nature, 215, 1187-1188.

Kitamura, T., MiYagawa, Y. AND TANAKA, Y. (1973): Studies on a heat-labile variola virus inhibitor in normal sera. I. Detection by the variola focus reduction assay and its general characteristics. Intervirology, 1, 278-287.

KitAmuRA, T., TANAKA, Y. AND SUgANE, M. (1973): Studies on a heat-labile variola virus inhibitor in normal sera. II. Further characterization of the inhibitor and its activity. Intervirology, 1, 288-296.

MCINTOSH, J. AND SCARFF, R. W. (1930): The reaction of the central nervous system to vaccinia virus. J. Pathol. Bacteriol., 33, 483-488.

TAgaya, I., Kitamura, T. AND Sano, Y. (1961): A new mutant of dermovaccinia virus. Nature, 192, 381-382.

Tagaya, I., Amano, H., Kitamura, T., Komatsu, T., Ueda, Y., Tanaka, Y,. Uchida, N. AND KodAma, H. (1973): Properties of an attenuated mutant of vaccinia virus, strain DIs. Symp. Series immunobiol. Standard. (S. Karger), 19, 299-307.

TAGAYA, I., AMANO, H. AND YUASA, T. (1974): Improved plaque assay of a mutant of vaccinia virus, strain DIs, in chick embryo cell cultures. Japan. J. Med. Sci. Biol., 27, $245-247$.

UedA, Y., TAgaya, I., Amano, H. AND ITo, M. (1972): Studies on the early antigens induced by vaccinia virus. Virology, 49, 794-800. 